\title{
Creating a DEBT
}

\author{
Derek Richards \\ Editor, Evidence-based Dentistry
}

Evidence-Based Dentistry (2007) 8, 2. doi: 10.1038/sj.ebd.6400484

In a Toolbox article several years ago, one of our editorial board raised the concept of the critically appraised topic (CAT). ${ }^{1}$ The CAT is a short summary of the evidence on a particular clinical topic or question. Acronyms besides CAT have emerged in medicine over the years: BET (Best Evidence Topics; see www.besstbets.org) and POEMs (Patient Orientated Evidence that Matters; see www.infopoems.com), for example, and there are also the Evidence-based Journal Club Reviews. A search engine for medical CAT is available (see www.bii.a-star.edu. sg/achievements/applications/catcrawler/ cat_search.asp).

I believe that the time is now right to encourage the development of CAT in dentistry, so we are going to introduce a new feature into the journal: Dental Evidencebased Topics (DEBT). There are a number of tools and resources that are available to assist you in preparing a CAT or DEBT. I will highlight some of these as I outline what a DEBT should include.

Title. This should be short, catchy and relevant to the topic.

Clinical bottom line. This should be a couple of sentences at the most, highlighting the main findings - similar to the practice points we use in Summaries in Evidence-based Dentistry. Examples of clinical bottom lines in CAT can be found in the Centre for Evidence-based Medicine's CATbank (www.minervation.com/cebm2/ cats/allcats.html).
Clinical scenario. The clinical situation that gives rise to the question should be outlined. For example, during a routine examination of a preschool child (living in a fluoridated community), you point out an early carious lesion in a deciduous molar. The child' mother then asks you,

"Should I be using fluoridated toothpaste?". If you have a good clinical image to represent the clinical problem you could also submit that.

Clinical question. Clarifying or formulating the main question is a key skill for evidence-based practice, and the 'PICO' format, described in a previous issue of the journal ${ }^{2}$ and widely used in evidence-based practice, is the format that should be used. The letters stand for:

Population, patient or problem

Intervention or treatment, or Exposure or potential risk factor

\section{Comparison}

\section{Outcome}

The scenario outlined above may raise many questions; in some evidence-based workshops I have encountered 20 slightly different questions. What you need to decide is which question is most relevant to your clinical practice. For the scenario above, I believe that the question is, "Would using a fluoride toothpaste provide additional caries prevention in preschool children who live in a fluoridated water area?" See Table 1 for the question in PICO format.

Search terms used. Once the question has been defined, an electronic search can be

Table 1. PICO categories for our clinical question

\begin{tabular}{|c|c|c|c|}
\hline Population & Intervention & Comparison & Outcome \\
\hline $\begin{array}{l}\text { Preschool children in } \\
\text { a fluoridated water area }\end{array}$ & Fluoride toothpaste & $\begin{array}{l}\text { Non-fluoride } \\
\text { toothpaste }\end{array}$ & Reduced caries \\
\hline
\end{tabular}

conducted. Medline is the database most accessible to most people because it is available free of charge, via the PubMed interface (www.pubmed.gov), but there are a wide range of databases available (eg, Cochrane Library, Cumulative Index to nursing and Allied Health Literature (CINHAL), PsychLit, Latin American and Caribbean Health Sciences Literature (LILACS), Educational Information Resource Center (ERIC). Ideally the databases most relevant to the questions being considered should be used.

Table 2 outlines a brief search undertaken to answer the PICO question above. In preparing a DEBT for $E B D$ the search should be written in the following format \{(toothpaste) OR ("Toothpaste"[Mesh]) OR (dentifrice) OR ("Dentifrices"[Mesh]) AND (Fluoride) AND (Caries) OR ("Dental

Table 2. Example of a Medline search to address the PICO question

\begin{tabular}{|c|c|c|}
\hline Search & Search term & Result \\
\hline 1 & toothpaste & 2486 \\
\hline 2 & "toothpaste"[Mesh] & 1705 \\
\hline 3 & dentifrice & 4490 \\
\hline 4 & "dentifrices"[Mesh] & 4264 \\
\hline 5 & fluoride & 35992 \\
\hline 6 & caries & 35435 \\
\hline 7 & "dental caries"[Mesh] & 29860 \\
\hline 8 & 1 or 2 or 3 or 4 & 4988 \\
\hline 9 & 5 and 8 & 2522 \\
\hline 10 & 6 or 7 & 35509 \\
\hline 11 & 9 and 10 & 1289 \\
\hline 12 & limits: meta-analysis & 22 \\
\hline
\end{tabular}


Caries"[Mesh]) Limited to (Meta-Analysis)\}. Studies identified. Here, the important studies identified need to be described. Because the DEBT is intended to be a short summary, it is worth considering using a hierarchy. A useful one is:

- High-quality guidelines

- Cochrane reviews

- Systematic reviews

- Studies

A more detailed hierarchy is available at the Centre for Evidence-based Medicine website (www.cebm.net/index. aspx?o=1025). In many instances there will be few high-quality studies addressing your questions. What you find could be summarised in table form, using headings similar to those used in BEST BETS (Table 3).

Critical appraisal is another important skill of evidence-based practice that will help you evaluate the merit of the paper. Some useful tools to help you do this are available on the Centre for Evidence-based Dentistry website (www.cebd.org/?o=1053). In the example above, the search identified 22 meta-analyses. Looking at the titles of these, there are four Cochrane Reviews identified that could be relevant to answering the question.

Discussion. This section should include a discussion of the papers identified, commenting on strengths and weaknesses and relating the information in the papers to the clinical scenario initially described.

The review of fluoride toothpastes for preventing dental caries in children and adolescents, found that, "The effect of fluoride toothpaste increased with higher baseline levels of $\mathrm{D}(\mathrm{M}) \mathrm{FS}$, higher fluoride concentration, higher frequency of use, and supervised brushing, but was not influenced by exposure to water fluoridation." This suggests that you could advise the mother that using fluoride toothpaste would provide additional benefit. It should be borne in mind, however, that only a limited number of the studies included in the review were conducted on the deciduous dentition so this is extrapolating from the evidence presented. It would also be worth providing the toothbrushing advice from the evidencebased guideline developed by the Scottish Intercollegiate Network for preschool children: ${ }^{7}$ "Children should have their teeth brushed, or be assisted with toothbrushing by an adult, at least twice a day, with a smear (under 2 years) or pea-sized (over 2) amount of fluoride toothpaste."

References. The DEBT should be fully referenced according to the format described in $E B D$ 's author guidelines.

Having outlined how to produce a DEBT I encourage you to submit them to the journal, preferably electronically as rich text format (rtf) files to ebdeditor@nature.com

1. Sequeira P. Critically appraised topics (CATs): bringing evidence to the chairside (1). Evid based Dent 2000; 2:107-109.

2. Richards D. Asking the right question right. Evid based Dent 2000; 2:20-21.

3. Marinho VC, Higgins JP, Sheiham A, Logan S. Combinations of topical fluoride (toothpastes, mouthrinses, gels, varnishes) versus single topical fluoride for preventing dental caries in children and adolescents. Cochrane Database Syst Rev 2004; issue 1.

Table 3. Suggested headings for summarising studies in a DEBT

\begin{tabular}{l|l|l|l|l}
\hline $\begin{array}{l}\text { Author, date, } \\
\text { country }\end{array}$ & Patient group & $\begin{array}{l}\text { Study type/ } \\
\text { level of } \\
\text { evidence }\end{array}$ & Outcomes
\end{tabular}

4. Marinho VC, Higgins JP, Sheiham A, Logan S. One topical fluoride (toothpastes, or mouthrinses, or gels, or varnishes) versus another for preventing dental caries in children and adolescents. Cochrane Database Syst Rev 2004; issue 1.

5. Marinho VC, Higgins JP, Logan S, Sheiham A. Topical fluoride (toothpastes, mouthrinses, gels or varnishes) for preventing dental caries in children and adolescents. Cochrane Database Syst Rev 2003; issue 4.

6. Marinho VC, Higgins JP, Sheiham A, Logan S Fluoride toothpastes for preventing dental caries in children and adolescents. Cochrane Database Syst Rev 2003; issue 1.

7. Scottish Intercollegiate Guidelines Network. Prevention and management of dental decay in the pre-school child. A national clinical guideline. SIGN publication no.83. Edinburgh: Scottish Intercollegiate Guidelines Network ; 2005:p41.

\section{CORRECTION}

\section{Topical fluoride guidance}

In Volume 7(3) pp62-64 we summarised the American Dental Association's guideline on professionally applied fluoride. The following sections of the summary were used as follows:

Tables 1 and 2 (p62) and Table 5 (p63) were reprinted from Tables 1, 2 and 3 of the original article.

Table 4 (p63) was adapted from Box 2 of the original article.

Table 3 was adapted verbatim from the original article as was the section on Recommendations for Research.

The commentary should have included the following credit line:

American Dental Association Council on Scientific Affairs. Professionally applied topical fluoride: evidence-based clinical recommendations. J Am Dent Assoc 2006; 137:1151-1159. C2006 American Dental Association. All rights reserved.

It should also have included a credit line for Table 2 which was amended with permission by the BMJ Publications Group from Shekelle PG, Woolf SH, Eccles M, Grimshaw J. Clinical guidelines: developing guidelines.1999; 318:593-596. 